\section{High-Resolution Angioscopy of Endoluminal Stent Graft at 6 Months After Implantation}

\author{
Makoto Hoyano, MD, PhD; \\ Kazuyuki Ozaki, MD, PhD; Kota Nishida, MD; \\ Ryohei Sakai, MD; Naoki Kubota, MD; \\ Toshiki Takano, MD; Takeshi Okubo, MD; \\ Shinpei Kimura, MD, PhD; \\ Takao Yanagawa, MD, PhD; \\ Takuya Ozawa, MD, PhD; \\ Takeshi Kashimura, MD, PhD; \\ Tohru Minamino, MD, PhD
}

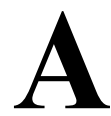

75-year-old man with long occlusion of the right superficial femoral artery (SFA) had undergone 2 Viabahn ${ }^{\circledR}$ (WL Gore \& Associates, AZ, USA) 5.5-150-mm and $6.0-100-\mathrm{mm}$ implantations 6 months previously (Figure A,B). As anti-thrombotic treatment, clopidogrel $75 \mathrm{mg} /$ day and aspirin $100 \mathrm{mg} /$ day were given for 1 month, and then clopidogrel was discontinued. Follow-up angiogram demonstrated no restenosis at the implant site (Figure C). Angioscopy (Zemporshe ${ }^{\circledR}$, OVALIS, Osaka, Japan) showed several thin linear longitudinal thrombi and the naked graft on the inside of the Viabahn (Figure D,E). At the distal edge of the Viabahn, we observed a step between the stent graft and native SFA (Figure F). Neointimal proliferation or plaque growth were not observed.
Stent graft thrombosis is the disadvantage of covered stents. Edge restenosis is a known factor for Viabahn stent graft thrombosis. ${ }^{1}$ In the present case, the edge of the stent was smooth and did not show restenosis.

The Zemporshe high-resolution angioscope is equipped with a 0.48 -megapixel equivalent resolution camera. In this case, Zemporshe could clearly visualize the histopathology inside the Viabahn implanted to the SFA.

\section{Disclosures}

The authors declare no conflicts of interest.

\section{Reference}

1. Geraghty PJ, Mewissen MW, Jaff MR, Ansel GM; VIBRANT Investigators. Three-year results of the VIBRANT trial of VIABAHN endoprosthesis versus bare nitinol stent implantation for complex superficial femoral artery occlusive disease. $J$ Vasc Surg 2013; 58: 386-395.e4.

Received December 11, 2018; revised manuscript received January 14, 2019; accepted January 27, 2019; J-STAGE Advance Publication released online March 7, 2019 Time for primary review: 28 days

Department of Cardiovascular Biology and Medicine, Niigata University Graduate School of Medical and Dental Sciences, Niigata, Japan

Mailing address: Makoto Hoyano, MD, PhD, Department of Cardiovascular Biology and Medicine, Niigata University Graduate School of Medical and Dental Sciences, 1-754 Asahimachidori, Chuo-ku, Niigata 951-8510, Japan. E-mail: med-hoy@mail.goo. ne.jp

ISSN-1346-9843 All rights are reserved to the Japanese Circulation Society. For permissions, please e-mail: cj@j-circ.or.jp
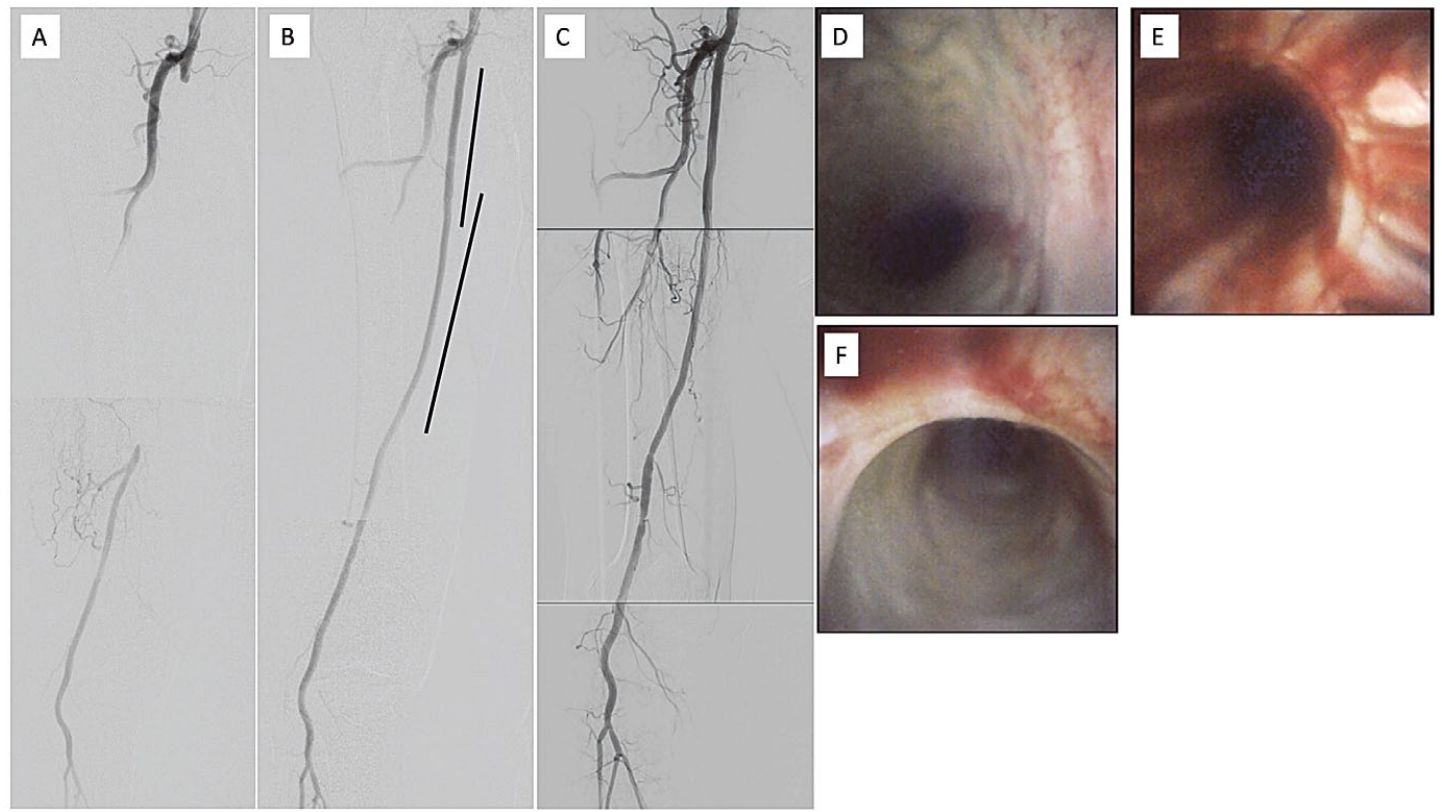

Figure. (A) Baseline angiography showing long total occlusion in the right superficial femoral artery. (B) Lines, Viabahn implantation sites. (C) Six-month follow-up angiography showing good expansion. (D) Angioscopy showing the naked graft and (E) several longitudinal thrombi. (F) At the distal edge of the Viabahn, a step was observed. 